\title{
Secure Energy Efficient Automated Ticketing System
}

\author{
V. Sumitra, A. Iyswariya, P. Latha, K. Jeevitha,
}

\begin{abstract}
A ticketing-based system on beacons is an energy efficient system developed for industry. An IoT monitoring system is implemented for temporary visit people, interviewees in the industry. During their visits they need not to submit their original ID proof to the office receptionist, which may lead to any misuse and discomfort. A model is proposed which is totally differing from the present system. Whenever a person wants to visit any company, the details are being registered in the app designed according to the company; these data are being sent to the web server. They need to on their beacon in mobile or any beacon supporting devices when entering the company. The monitor system connecting the Master beacon receives the receiver beacon ID and is being compared with the database in the server. The data are being received by the microcontroller. The thermal printer connected to the microcontroller will print the data of the person visiting the company, his purpose, date and time which is used for the further verification. This model is implemented to prevent human intervention.
\end{abstract}

Keywords - Beacon module, thermal printer, Arduino mega, mobile app

\section{INTRODUCTION}

IoT is used to refer to the concept that describes the idea of everyday things connected to the Internet or the cloud to connect various actions. This has kindled the integration of billions of embedded devices into our surroundings. Through smart applications, these connected devices promise to improve our lives by communicating and exchanging data seamlessly without any (or minimal) human intervention. An automated public transport ticketing system is one such application. Smartcard-based public transport ticketing systems are popular in the last two decades as it relives the commuters and the service providers from the burden of buying/selling tickets for each journey. However, the passengers have to register their journeys through check-in and check-out by placing the card near the tracking devices installed in the vehicles, at the stations, etc. [1]. The process becomes annoying for daily commuters if they have to use multiple modes of transportation, such as bus, train, tram, etc., or if the journey involves different segments. Many investigations have been done to improve the public transport

Revised Manuscript Received on 30 July 2019.

* Correspondence Author

Ms. V. Sumitra, ECE, R.M.K. Engineering College, Chennai, India.

Ms. A. Iyswariya, ECE, R.M.K. Engineering College, Chennai, India Ms. P. Latha, , ECE, R.M.K. Engineering College, Chennai, India

Ms. K. Jeevitha, , ECE, R.M.K. Engineering College, Chennai, India

(C) The Authors. Published by Blue Eyes Intelligence Engineering and Sciences Publication (BEIESP). This is an open access article under the CC-BY-NC-ND license http://creativecommons.org/licenses/by-nc-nd/4.0/ ticketing system using smartcards but none of these solutions is feasible for a fully automated ticketing system without any human intervention. Hence a smart phone-based application that communicates with tracking devices and registers the journey automatically. Using this concept, a proposed model is done which uses the smart phone-based and cloud to store the data base of the temporary people, interviewees to enter any company without any human intervention. This mainly saves the time of the people and even the people do not necessarily carry their documents to whose ever company they need to visit. The people who need to visit any company can register their complete details in the mobile app and it will be stored on the web cloud of the particular company [9]. Modern smart phones are equipped with various modes of wireless connectivity, e.g., Wi-Fi, GSM, Bluetooth, NFC, etc. For this application, wireless communication technology is needed that offers Omni directional transmission with a range of at least a couple of meters, low data rate, and low energy consumption. Bluetooth Low Energy (BLE) is a technology for wireless personal area networks, which is designed for low energy consumption applications [5]. Moreover, users are familiar with Bluetooth. Thus, Bluetooth can be an ideal for this application[10]. The proposed system does the task like making the people to enter the company more precisely and decreasing human work and errors like misuse of documents by use of BLE (Bluetooth Low Energy) beacon [4]. For making work faster and not keeping them wait for a long time and keeping we can make use of this proposed technique.

\section{LITERATURE REVIEW}

\section{"Smart Transport Ticketing System Using IoT", by Shreyas Mahangade}

In Ticketing system based on RFID technology passenger have a RFID tag, containing unique ID and kindred data. when passenger boards the vehicle RFID readers in the vehicle detect the tag, collects the data and sends to computing device which records the location and sends to database with the help of GPS and GSM module respectively. After the passenger gets off the vehicle the computing device calculates the fare as per the distance travelled and deducts the corresponding amount from the account of the passenger [2].

"Smart College System using IoT BLE Beacons", by Ankit .S. Barapatre

The traditional systems does marking of attendance, handling lectures by paper signing pattern which disturbs the concentration of students but on research, proposed idea does task like automated marking attendance by use of BLE (Bluetooth Low Energy) 


\section{Secure Energy Efficient Automated Ticketing System}

Eddy stone beacons and the involves usage of automated tools like Selenium which will be reducing the paper work and error like proxy, missing attendance. The system also gives the idea about many events and programs by advertising their details and providing details of examinations in the college campus on reaching the place so system alerts the students if the lecture starts and they are outside the classroom. For making better decisions and keeping eye on everyone and to save students time and reduce their disturbance in lectures. It is using - concept of proximity analysis solution using BLE 4.0Technologyll which results to digitizing college activities and reduction of disturbance in concentration and also reduction in workload of staff for attendance manipulation and other activities, we can make use of this proposed technology using BLE 4.0 beacons.[3] This system solves all the problem occurred in college indoor area. The previous system uses more hardware device for college activities like marking attendance, managing events and instructing for exam location which takes a long time for all the students to do that type of work

"How low energy is bluetooth low energy? Comparative measurements with zigbee/802.15.4," by

\section{Siekkinen}

Bluetooth is used for short range communications with Limited device density and frequency hopping based interference between independent Bluetooth piconets. with the development of Internet of Things, there is an abrupt increase in Bluetooth-equipped devices which gives raise to multiple collocated piconets, thus increasing the mutual interference which leads to performance degradation of Bluetooth. In this work the latency and energy consumption by Bluetooth low energy (BLE) devices under the influence of mutual interference, is studied and models are developed which can be utilized in future BLE devices.

\section{EXISTING SYSTEM}

The system uses Beacon based public transportation monitor system is implemented for fair collection from the people it's based on the beacon tracking system, but there is not suitable for the public transportation in due to the large population in the metro city. The passengers have to check-in and check-out by placing the card near the tracking devices installed in the vehicles etc which becomes annoying for commuters who uses multiple modes of transportation.

\section{PROPOSED SYSTEM}

In regarding to the existing system we developed same concept for industries, company. This same concept can be used in various other places where registration is mandatory. An IOT based monitor system is implemented for people in the industry. During the company visit, the temporary visit need not to carry their ID proofs every time. And some people refuse to handle their original ID proof by the office receptionist which may even lead to misuse. So in this project we develop a new concept totally differing from the present system. When the person wants to visit the office, they want to register the complete details in the mobile app available, these details are sent to the server. If the people enter into the office they want to turn on the beacon in the mobile.[6]The monitor system receives the beacon ID and compare with the database in the server which is sent to communication eliminating the chances of mutual

microcontroller connected to thermal printer. If the data matches the person will be issued a gate pass which is useful for future verification.

\section{BLOCK DIAGRAM}

\section{A. Receiver System}

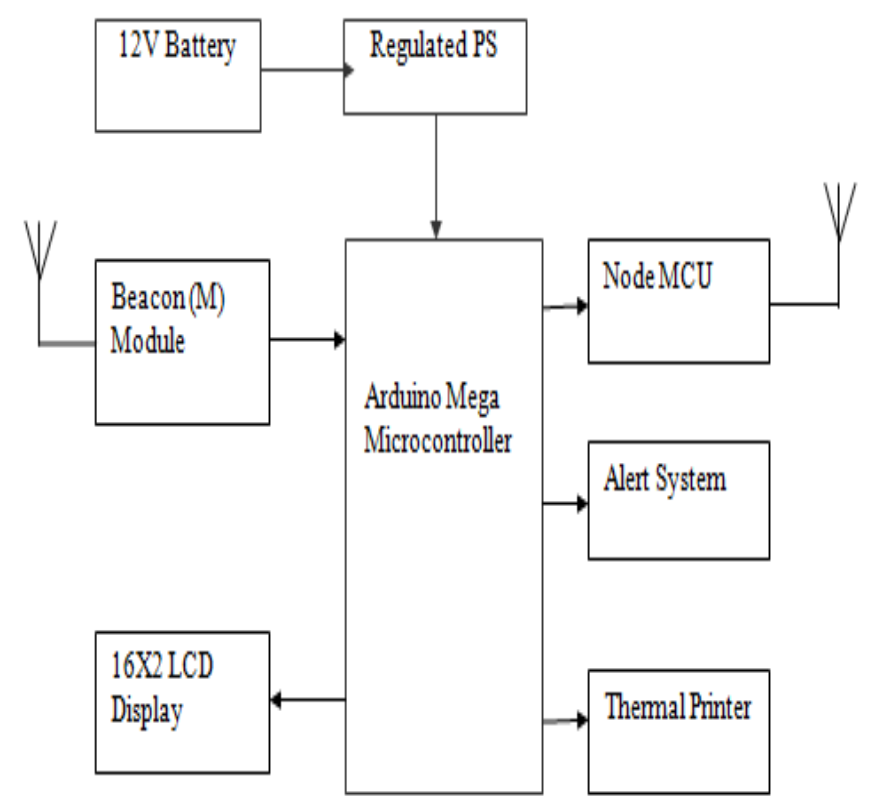

The receiver section consists of Arduino Mega Microcontroller to which components like Beacon Module, 16*2 LCD Display, Power Supply, Thermal Printer, Node MCU, Alert System are connected. The receiver section is given to the company for the reference. Beacon acts as a master in the receiver part and it works simultaneously and it is the alternative for the Bluetooth. Node MCU is an open source IoT platform which includes firmware runs on the ESP8266 WIFI. The Node MCU is connected serially with the Thermal printer, Beacon Module to the serial ports of Arduino. The Node MCU takes the internet connection through the modem of the company to which it is connected. The master Beacon searches for the slave Beacon Id continuously, once the slave Id matches with the existing Id in the master then the data has been received from the IOT cloud. The details received by the IOT cloud are being displayed on the web server of the company. Now simultaneously the LCD display displays the slave Beacon Id on the screen after which the thermal printer comes into action. The thermal printer produces an image by selective heating, coated thermo chromic paper. The thermal printer prints the details of the person, his purpose of visit, date and time and Id of the slave Beacon. The power supply for the receiver unit is taken from the direct supply. The Arduino Mega can be energized by using either USB connection or non-USB (AC-to-DC adapter or battery).

Published By:

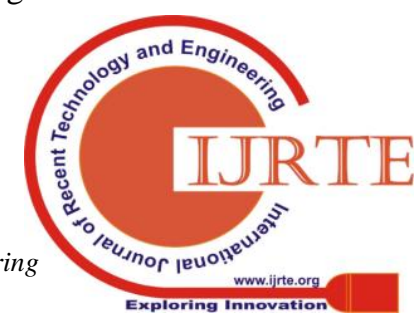




\section{B. Transmitter System}

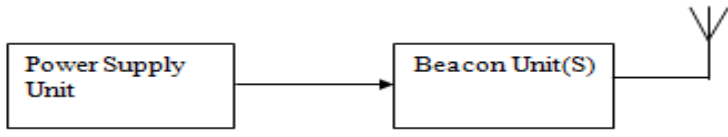

The transmitter system consists of Beacon unit and a Power supply unit. Beacon acts as slave in the transmitter part and it works simultaneously and it is the alternative for the Bluetooth. The distance of data transmission is small compared to other modes of wireless communication in the Beacon. The temporary visit people register their details through mobile application which will get stored into the cloud and then from there id information gets transferred to the master Beacon in the receiver system. When multiple number of receiver systems are present the action takes place in series one after the other with respect to the receiving system. After the master and slave beacon Id's are matched the receiver part proceeds with its operation.

\section{SOFTWARE IMPLEMENTATION}

\section{A. Web Page}

In this we create a webpage which is being monitored by the company. In this using login page the company registers the details of the company and gets login. The master beacon module is present in the company which is on all the time. Once the person who needs to enter into any company registers their details from the mobile [7] app these data's are being sent to the cloud and from which it reaches to the web page. The details in the webpage are being displayed according to the people's registration through their mobile app simultaneously [8]. In this the front end technology used is HTML and the back end process used is PHP.

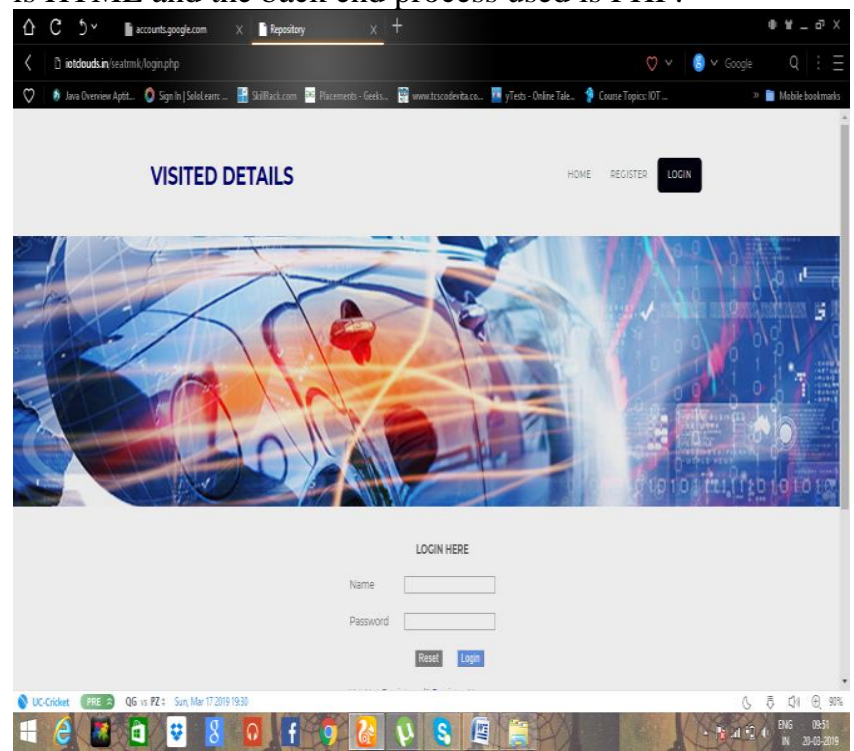

Fig1. Login Page.
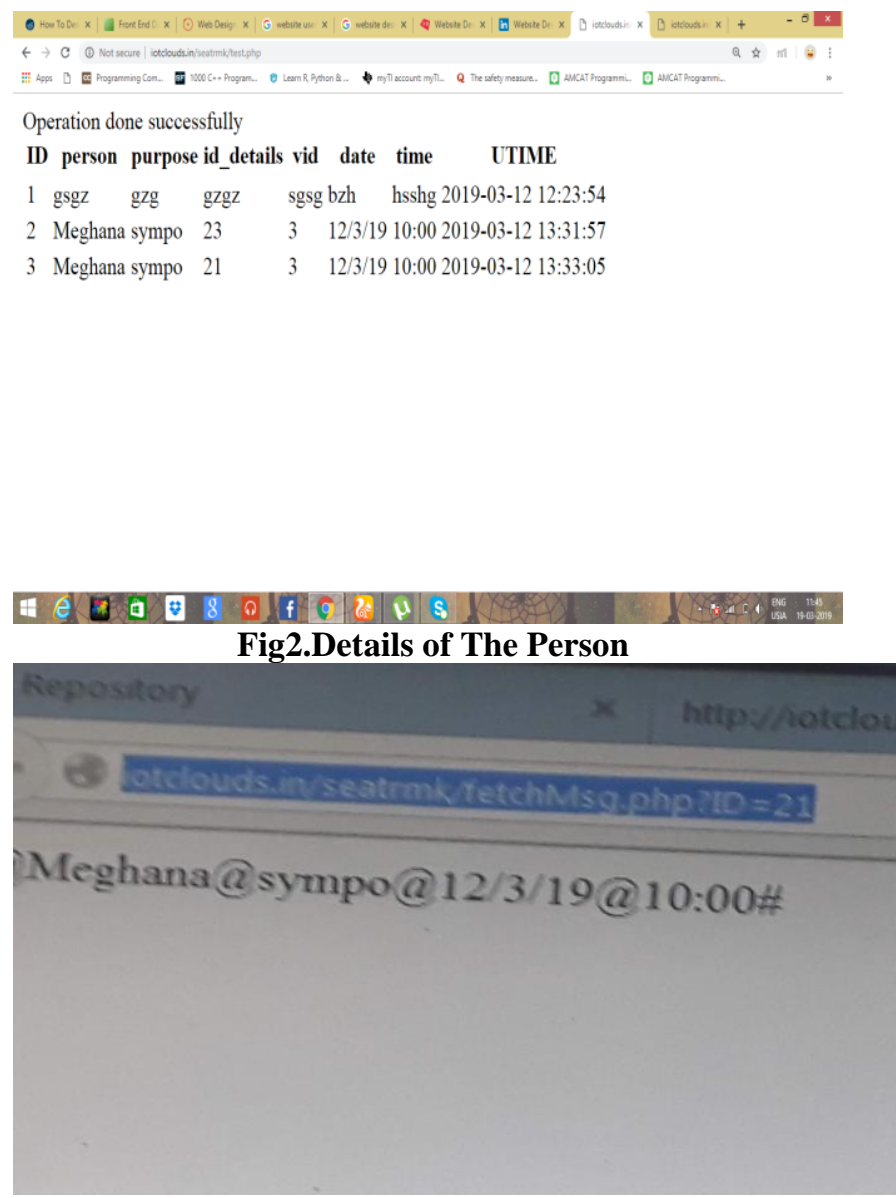

Fig3.Details Printed

\section{B. Mobile Application:}

The mobile application is used for the persons to register their details regarding their visit to the company. The mobile application is designed based on the requirements of the company. Before the visit of the person he needs to install the mobile app and register in the application using their email ID's.Later they can fill their details which includes name, purpose of visit, beacon ID, date. Later these data are being sent to the cloud and which is further stored in the cloud. Now the details are automatically seen in the webpage of the company. The front-end technology used here is the Java. 


\section{Secure Energy Efficient Automated Ticketing System}
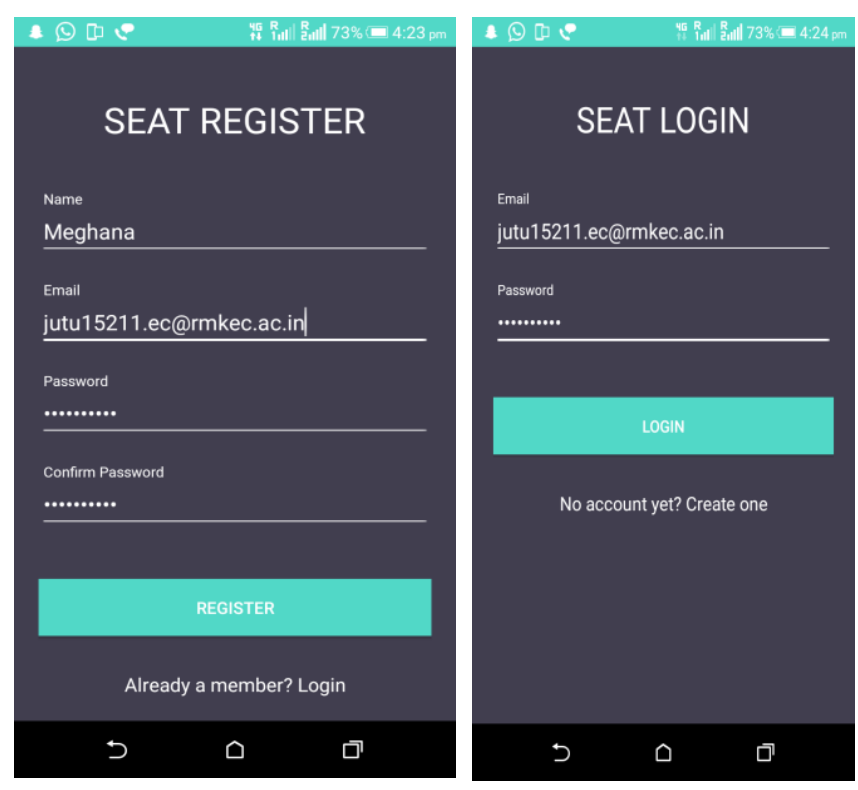

Fig4.Registration Page and Login Page

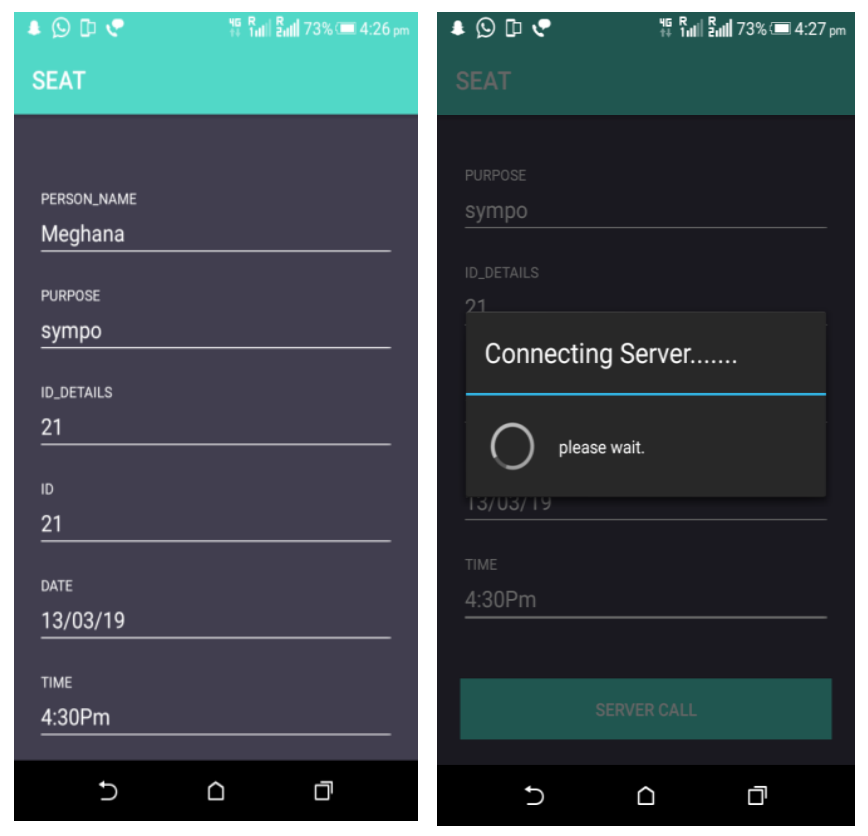

Fig5.Data Uploaded

\section{CONCLUSION}

An IOT based monitoring system is implemented for people in the industry. If the people enter into the office they want to turn on the beacon in the mobile. The monitor system receives the beacon ID and compare with the database in the server which is sent to microcontroller connected to thermal printer. If the data matches the person will be issued a gate pass which is useful for future verification.The beacon module used for many reasons like on two major aspects low energy consumption without interference and an automated system without any human intervention. This application offers consistency, time savings and simple control. It can be used as a base for creating similar applications for tracking attendance, event, and location in colleges and in offices or any workplace. In future, packet size can be increased to improve the data rate of the BLE devices.

\section{REFERENCES}

1. Chayan Sarkar , Jan Jaap Treurniet, Sujay Narayana,R. Venkatesha Prasad, and Willem de Boer,"SEAT:Secure Energy-Efficient Automated Public Transport Ticketing System", IEEE Transctions on green communications and networking, vol. 2, no. 1, March 2018

2. Rahul Khose, Shreyas Mahangade, Vicky Salunkhe, Nikhil Angane, Poonam Gupta , "Smart Transport Ticketing System Using IoT”, Vol 5, Issue 3, March 2018

3. Ankit .S. Barapatre, Vishal .A. Shelake, Gurudev .Y. Pawar, D.R.Anekar, "Smart College System using IoT BLE Beacons",vol 6, Issue 4, April 2017

4. W. Narzt, S. Mayerhofer, O. Weichselbaum, S. Haselböck, and N. Höfler,"Bluetooth low energy as enabling technology for be-in/be-out systems,"in Proc. 13th IEEE Annu. Consum. Commun. Netw. Conf. (CCNC), 2016

5. Wolfgang Narzt, Stefan Mayerhofer, Otto Weichselbaum Stefan Haselbock, Niklas Höfler,'Be-In/Be-Out with Bluetooth Low Energy: Implicit Ticketing for Public Transportation Systems", IEEE 18th International Conference on Intelligent Transportation Systems, Sep 2015

6. M. Siekkinen, M. Hiienkari, J. Nurminen, "How low energy is bluetooth low energy? Comparative measurements with zigbee/802.15.4," Wireless Communication and Networking Conference Workshop, April 2016

7. Reetesh V. Golhar; Prasann A. Vyawahare ; Pavan H Borghare ; Ashwini Manusmare, "Design and implementation of android base mobile app for an institute",in International Conference on Electrical, Electronics, and Optimization Techniques (ICEEOT),vol 5,no 2,march 2016

8. Raj, R., and Tolety.S, “ A study on approaches to build cross-platform mobile applications and criteria to select appropriate approach", India Conference (INDICON), 2012 Annual IEEE, 625-629.

9. PunamKumari and Rainu Nandal, "A Research Paper OnWebsite Development OptimizationUsing Xampp/PHP”, International Journal of Advanced Research in Computer Science Volume 8, No. 5 , May-June 2017

10. JayKiruthika, SouheilKhaddaj, Darrel Greenhill, Jarek Francik, "User Experience Design in Web Applications", IEEE Intl Conference on Computational Science and Engineering (CSE) , vol 4,no 9,Aug 2016

\section{AUTHORS PROFILE}

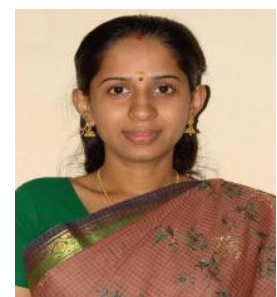

Ms V.Sumitra received her B.E degree in Electronics and Communication Engineering from Bharathiyar University, M.E degree in Applied Electronics from Sathyabama University, and pursuing Ph.D. degree from the Anna University, Chennai. She is Currently working as Associate Professor at R.M.K Engineering College,Tamilnadu.India Her research interest is in VLSI design and networking. She is a life member of the Indian society of technical education and also member of IACSI

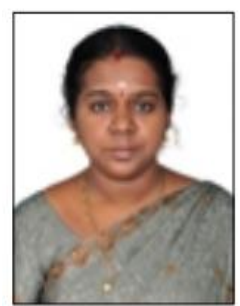

Ms.P.Latha was received the B.E. degree in Electronics and Communication Engineering from the Madras university, India, in 1998, M.E. degree in Applied Electronics from Anna University, chennai ,India in 2007. in R.M.K Engineering College,Tamilnadu, India. She is Currently working as Associate Professor at R.M.K Engineering College,Tamilnadu.India and doing her Ph.D in VLSI at Anna University. Her research interest is in VLSI design and networking. She is a life member of the Indian society of technical education and also member of IACSI.

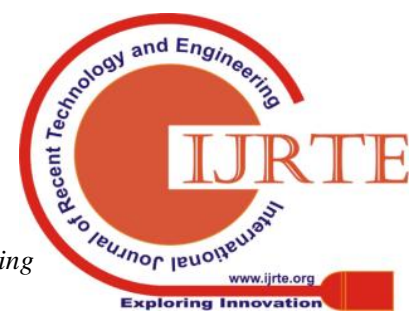




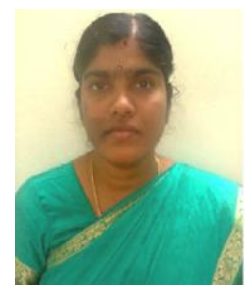

Ms.K.Jeevitha, was received the B.E. degree in Electronics and Communication Engineering from the Anna University, India, in 2005 and M.E. degree in Applied Electronics from Anna University, Chennai ,India in 2010. She is Currently working as Assistant Professor at R.M.K Engineering College, Tamilnadu,India and her research interest is in VLSI design and Embedded System. She is a life and also member of IACSI

member of the Indian society of technical education

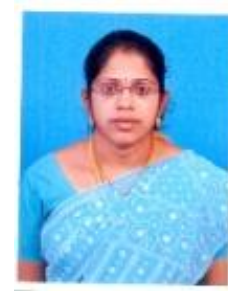

Ms.Iyswariya A received her B.E degree in Electronics and Communication Engineering and M.E. in Applied Electronics from M.N.M. Jain Engineering College ,affiliated to Anna University , Chennai. She is currently working as Assistant Professor in R.M.K. Engineering College, Chennai, Tamil Nadu , India. Her research interests are Image Processing and VLSI design. She is a life member of the Indian society of technical education. 